\title{
Lattice Boltzmann Method of a Flooding Accident at Gopeng, Perak, Malaysia
}

\author{
Siti Habibah Shafiai, Diana Bazila Shahruzzaman, Goh Juin Xien, and Mohamed Latheef \\ Department of Civil and Environmental Engineering, Universiti Teknologi PETRONAS, 32610 Bandar Seri Iskandar, Perak, Malaysia \\ Correspondence should be addressed to Siti Habibah Shafiai; sitihabibah.shafiai@utp.edu.my
}

Received 20 April 2017; Accepted 31 May 2017; Published 16 August 2017

Academic Editor: Jian G. Zhou

Copyright ( 2017 Siti Habibah Shafiai et al. This is an open access article distributed under the Creative Commons Attribution License, which permits unrestricted use, distribution, and reproduction in any medium, provided the original work is properly cited.

\begin{abstract}
The extraordinary flood had hit the residential area at Taman Raia Mesra, Gopeng, Perak, Malaysia, in November 2016. The event illustrated how the river basin had been fully inundated due to the heavy rainfall and caused the overflow to this affected area. It was reported that the occurrence became worst as the outlet of retention pond which connects to the river is unsuitable for the water outflow. Henceforth, this paper attempts to evaluate the causal factor of this recent disaster by using a model developed from Lattice Boltzmann Method (LBM). The model also incorporated with the rainfall and stormwater in LABSWE ${ }^{\mathrm{TM}}$. The simulation was commenced with the basic tests for model validation comprising turbulent and jet-forced flow in a circular channel, which resulted in a good agreement for both models. The simulation continued by using LABSWE model to reveal the water depth and velocity profile at the study site. These results had proven the incompatibility size of the outlet pond which is too small for the water to flow out to the river. The study is capable of providing the authorities with a sustainable design of proper drainage system, especially in Malaysia which is constantly receiving the outrageous heavy rainfall.
\end{abstract}

\section{Introduction}

A flood is well defined as the overflow of high water from the occupied water basin system including river and stream [1]. Flood is ranked as a third largest of the disastrous events among the Asian countries after wave surge and wind storm [2]. The occurrence can be dangerous to life and can lead to economic and properties loss. In Malaysia, a flood is not a new occasion especially for those who settled at the northeast of Peninsular Malaysia. Generally, the area will be flooded during northeast monsoon season held between October and March almost every year.

Perak which is located nearby the northeast state of Peninsular Malaysia is not exempted from the flood attacks. In December 2014, the state of Perak was affected by the astonishing flood on a scale that has never been experienced before. It is reported that more than 50 relief centres have been operated due to this event, with Perak Tengah as the most affected district. Typically, the cause of flood is a heavy continuous rainfall; however, the major triggering factor for the flood is the improper drainage system [3]. Yoon et al.
(2010) investigated that almost $30 \%$ of the flood is contributed by the improper setup of a drainage system, followed by pollution and urbanization management with $20 \%$ and $18 \%$, respectively [3]. The flood can affect one's life (death) and health including psychological or physiological problems [4].

Recognizing the adverse consequence of the flood, there is a need to demonstrate such a natural phenomenon by using a model or device that provides an accurate prediction. The Computational Fluid Dynamics (CFD) model applied in the water sector is a prevailing device to simulate the condition of the fluid especially in urban hydrology and water management field [5]. The ability to investigate the real situation by using a device can help to predict the future condition [6]. Hence, we benefit by comparing and improvising both theory and the real-life situations. There are numerous numbers of computer models for simulating the water sector including WEST, SIMBA, and MIKE. The evolution in technology enables the researchers to study their scope up to the microscopic scale, and today it is even possible to formulate the complex system. 
Lattice Boltzmann Method (LBM) is a modern computer model using High-Performance Computing (HPC) efficiently for fluid simulation within the complex geometries [7]. LBM is an advanced technique evolved from the Lattice Gas Automata (LGA) method. LGA method represents the macroscopic physical variables; meanwhile, LBM is able to solve the flow problem up to the microscopic equation [8]. LBM is proposed to allow an easy program and can be used for simulating the complex flow in complex geometries. The LBM comprised three criteria including lattice Boltzmann equation, lattice pattern, and local equilibrium distribution function. These tasks are responsible for forming a lattice Boltzmann equation for shallow water flows known as LABSWE.

The LABSWE had been applied in various conditions of water flow by many scientists including steady and unsteady flows, tidal flows, and turbulent flows in different dimensions [7]. The findings were compared with the physical modelling or analytical solutions in order to demonstrate their validation. The result shows that the accuracy of the LABSWE is very promising, hence proving the efficiency and capabilities of the method in simulating fluids.

The flood study by using the numerical approached had been explored by many researchers $[9,10]$. However, these studies focus on the scope of macroscopic result only. On the other hand, the study on flood is by using the LABSWE providing a microscopic outcome. The research may involve several variables including river profile, water flow direction, and water depth profile which help to estimate the future occurrence of the flood, hence reducing the risk of flood [11].

Taman Raia Mesra located at Gopeng, Perak, is under construction for the residential area. The project site is about 30 acres of land with the presence of retention pond located nearby the housing area. The retention pond is attached with the adjacent river by an outlet. In November 2016, the area was flooded which caused a major loss to the developer. The area received about $821 \mathrm{~mm}$ rainfall intensity throughout the event. The continuous heavy rainfall is causing the water from the nearby river, Sg Tekah, to overflow at the site. It is mentioned that the housing area was inundated by flood for about three days. The ground visit observed that one of the factors that may cause the flood is the size of outlet drainage of the retention pond which is too small.

The study was then started immediately after the event to overcome the problem. The LABSWE is used in this study to analyse the flood at Taman Raia Mesra. The model also incorporates in the LABSWE the rainfall and stormwater parameters that lead to the flood. The few basic tests were investigated for the model validation including turbulent flow and jet-forced flow in a circular channel. The simulation results of the study area are capable of providing the authorities with a sustainable design of proper drainage system at Taman Raia Mesra, Gopeng, Perak, hence, preventing the occurrence of a future flood at the site.

\section{Materials and Methods}

2.1. Lattice Boltzmann Model for Shallow Water Equation with Turbulent Flow (LABSWE). The LBM for shallow water

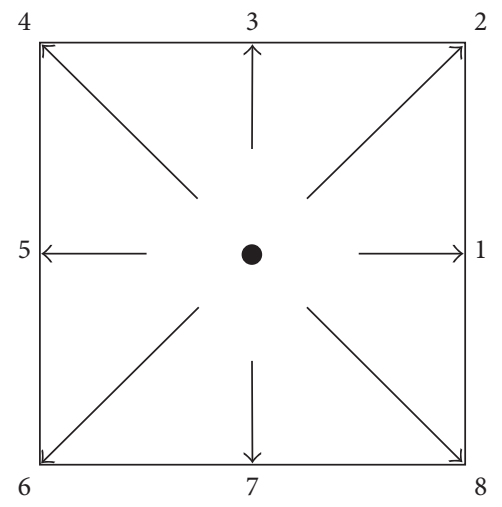

FIGURE 1: Lattice pattern with a 9-velocity square [12].

equation (LABSWE) based on the 9-velocity square lattice pattern is approached. The lattice pattern indicated the movement of the particle on a lattice unit at its velocity along one of the eight links specified 1-8 (Figure 1). Meanwhile, the zero value means the particle is at resting phase with zero speed.

The Lattice Boltzmann equation (LBE) can be determined as

$$
f_{a}^{\prime}\left(x+e_{\alpha} \Delta t, t+\Delta t\right)=f_{\alpha}(x, t)+\frac{\Delta t}{N_{\alpha} e^{2}} e_{a i} F_{i}(x, t),
$$

where $f_{a}$ is the particle distribution function; $e=\Delta x / \Delta t$, where $\Delta x$ is the lattice size and $\Delta t$ is the time. $N_{\alpha}$ is a constant determined by

$$
N_{\alpha}=\frac{1}{e^{2}} \sum_{\alpha} e_{a x} e_{a x}=\frac{1}{e^{2}} \sum_{\alpha} e_{a y} e_{a y} .
$$

There are two steps in LBM including streaming and collision. If the particles move at their own velocities towards their nearest neighbours, it is called streaming step. On the other hand, collision step occurs when the particles arrive at lattice point and have interaction with one another. This interaction, according to the scattering rules, will affect their velocities and direction. Hence, the new distribution function is expressed as

$$
f_{\alpha}(x, t)=f^{\prime} \alpha(x, t)-\Omega_{\alpha}\left[f^{\prime} \alpha(x, t)-f_{\alpha}^{\mathrm{eq}}(x, t)\right],
$$

where $\Omega_{\alpha}$ is the collision operator and $f_{a}^{\text {eq }}$ is the local equilibrium distributions function. The combination of streaming and collision steps in a 9-velocity square lattice modified the lattice Boltzmann equation as

$$
\begin{aligned}
f_{a}\left(x+e_{\alpha} \Delta t, t+\Delta t\right)= & f_{\alpha}(x, t) \\
& -\frac{1}{\tau_{t}}\left[f_{\alpha}(x, t)-f_{\alpha}^{\mathrm{eq}}(x, t)\right] \\
& +\frac{\Delta t}{6 e^{2}} e_{\alpha i} F_{i},
\end{aligned}
$$


where $\tau_{t}$ is the total relaxation time for modelling flow turbulence and can be calculated from

$$
\begin{aligned}
\tau_{t}= & \tau+\tau_{e^{\prime}} \\
\tau_{e} & =\frac{-\tau \sqrt{\tau^{2}+18 C_{S}^{2} /\left(e^{2} h\right) \sqrt{\Pi_{i j} \Pi_{i j}}}}{2} .
\end{aligned}
$$

In the equation above, $\tau_{e}$ is the eddy relaxation time, and $\Pi_{i j}$ is defined as

$$
\Pi_{i j}=\sum_{\alpha} e_{\alpha i} e_{\alpha j}\left(f_{\alpha}-f_{\alpha}^{\mathrm{eq}}\right)
$$

In order to identify the velocity vector of particles in the square lattice, the equation that follows will be approached:

$$
\begin{aligned}
& e_{\alpha} \\
& = \begin{cases}(0,0), & \alpha=0, \\
e\left[\cos \frac{(\alpha-1) \pi}{4}, \sin \frac{(\alpha-1) \pi}{4}\right], & \alpha=1,3,5,7 \\
\sqrt{2} e\left[\cos \frac{(\alpha-1) \pi}{4}, \sin \frac{(\alpha-1) \pi}{4}\right], & \alpha=2,4,6,8\end{cases}
\end{aligned}
$$

Hence, to solve the shallow water equations using LBM, a local equilibrium function is defined as

$$
f_{\alpha}^{\mathrm{eq}}= \begin{cases}h-\frac{5 g h^{2}}{6 e^{2}}-\frac{2 h}{3 e^{2}} u_{i} u_{i}, & \alpha=0, \\ \frac{g h^{2}}{6 e^{2}}-\frac{h}{3 e^{2}} e_{\alpha i} u_{i}+\frac{h}{2 e^{4}} e_{\alpha i} e_{\alpha j} u_{i} u_{j}-\frac{h}{6 e^{2}} u_{i} u_{i}, & \alpha=1,3,5,7, \\ \frac{g h^{2}}{24 e^{2}}-\frac{h}{12 e^{2}} e_{\alpha i} u_{i}+\frac{h}{8 e^{4}} e_{\alpha i} e_{\alpha j} u_{i} u_{j}-\frac{h}{24 e^{2}} u_{i} u_{i}, & \alpha=2,4,6,8,\end{cases}
$$

where $h$ is water depth and $u_{i}$ is flow velocity which can be obtained through

$$
\begin{aligned}
h & =\sum_{\alpha} f_{\alpha}, \\
u_{i} & =\frac{1}{h} \sum_{\alpha} e_{\alpha i} f_{\alpha} .
\end{aligned}
$$

2.2. Flood Model. There are a few parameters taken into account for the flood model in this study. The discharge rainfall (Q) was focusing on the data on November 2016 with the catchment area located in a nearby city; Ipoh is taken as a reference. The discharge can be calculated by using the Rational Formula based on urban Stormwater Management Manual for Malaysia (MSMA 2):

$$
Q=\frac{C \times i \times A}{360}
$$

where $Q$ is a peak flow $\left(\mathrm{m}^{3} / \mathrm{s}\right), i$ is the average intensity of rainfall, and $A$ is site area. $C$ is the coefficient of a rainfall that can be obtained from the table provided by MSMA 2 .

The discharge of a domestic waste usage is derived from the continuity equation

$$
Q=A V
$$

where $Q$ is a peak flow $\left(\mathrm{m}^{3} / \mathrm{s}\right), A$ is an average intensity of rainfall, and $V$ is the water velocity. The velocity of the water flow is obtained by using Manning's equation

$$
V=\frac{1}{n} R^{2 / 3} S^{1 / 2}
$$

In (12), $V$ is defined as the velocity of water in the drain $(\mathrm{m} / \mathrm{s}), n$ is Manning's Roughness coefficient obtained from the MSMA 2. $R(\mathrm{~m})$ is referred as a hydraulic radius and $S$ $(\mathrm{mm} / \mathrm{hr})$ is a drain slope.

For the simulation process, the inlet drainage to the river is set up with a rectangular channel with dimension and slope of $300 \mathrm{~mm} \times 600 \mathrm{~mm}$ and $S_{a}=0.002$, respectively. Meanwhile, the river nearby is defined to be rectangular stream channel with a flatbed bathymetry. The layout plan of the river is developed by integrating the AutoCAD system into LABSWE.

\section{Results and Discussion}

3.1. Turbulent Flow within a Channel with a Circular Cavity. The flow in a channel with a circular cavity is simulated to demonstrate the ability of the model in simulating the effect of the turbulent flow in a river attached to a lake [12]. The shape of the model prediction for the simulation is prepared as illustrated in Figure 2. The model is designed with a rectangular channel $1.89 \mathrm{~m}$ wide and $18.9 \mathrm{~m}$ long. The channel is attached to a circular sidewall cavity on the right side of the channel with a radius of $3.15 \mathrm{~m}$.

The simulation is set up to a constant value of flow velocity components, $u=0.25 \mathrm{~m} / \mathrm{s}$ and $v=0 \mathrm{~m} / \mathrm{s}$. The water depth is maintained at $h=0.25 \mathrm{~m}$. A $190 \times 70$ lattice with grid space of $\Delta x=0.1 \mathrm{~m}$ applied. A semislip boundary condition has a surface roughness coefficient $C f=0.0045$ and is used at the solid walls. The relaxation time and Smagorinsky constant are applied with $\tau=0.6$ and $C_{S}=0.3$, respectively. A time step of $\Delta t=0.03 \mathrm{~s}$ is applied in this model.

The model reached its steady state after 10000th iteration with relative error $E_{R}=5.24 \times 10^{-9}$. The fully convergence flow of velocity vectors and streamlines are generated in the cavity by the model as illustrated in Figures 3 and 4, respectively. 


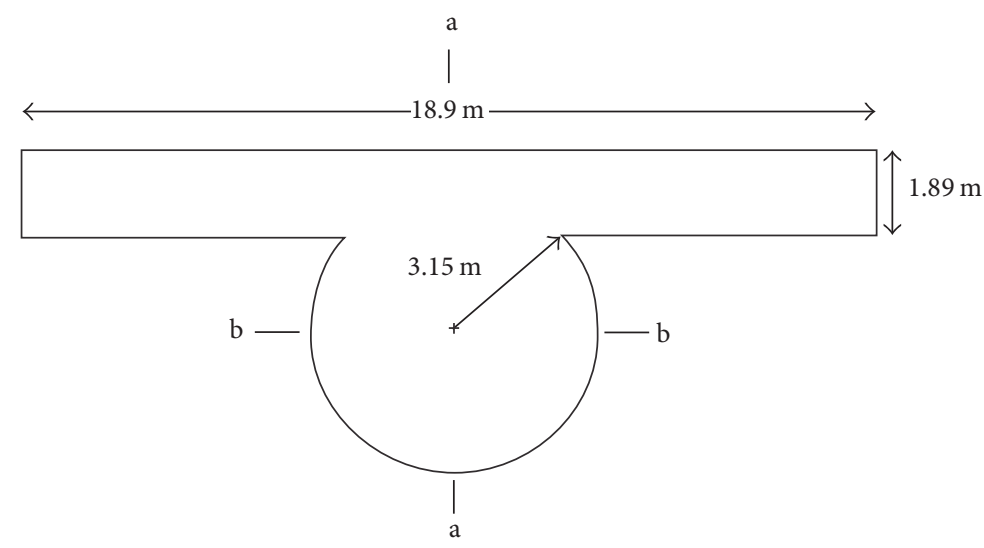

FIGURE 2: Dimension of the open channel with circular sidewall cavity [12].

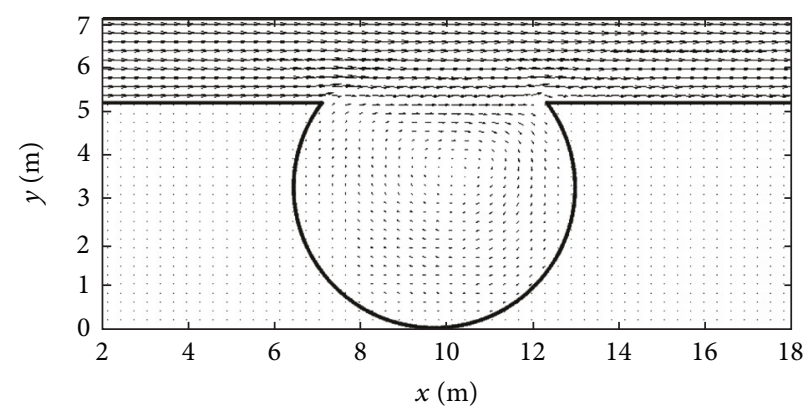

FIGURE 3: Velocity vectors in the circular sidewall cavity [12].

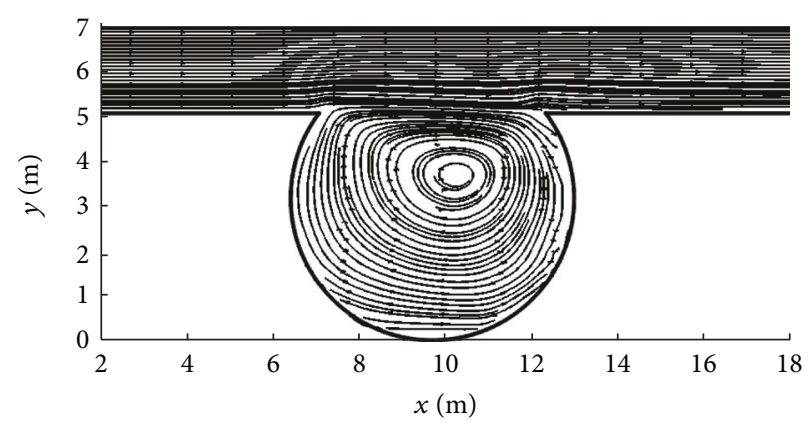

FIGURE 4: Streamlines flow in the circular sidewall cavity [12].

The $u$ and $v$ velocity components along the vertical (aa) and horizontal (b-b) cross section were validated (Figures 5 and 6) by comparing the data with data from Kuipers and Vreugdenhill (1973) [13]. The evaluation demonstrates that the model used in this study generates a better outcome than the previous data.

3.2. Turbulent Jet-Forced Flow in Circular Basin. The jetforced flow in the circular basin was simulated by using the LABSWE [12]. The model of the simulation is designed in the symmetrical shape which is a standard profile of the circular basin. The dimensions and flow parameters for the model are shown in Figure 7.
The simulation flow is prepared with the radius of a basin $r=1.0 \mathrm{~m}$ with an opening of inlet and outlet is at an angle of $\pi / 16 \mathrm{rad}$. The outlet position is separated by $7 \pi / 8 \mathrm{rad}$ from the inlet. The model is utilized with $280 \times 160$ lattice grid spacing $\Delta x=\Delta y=0.0125 \mathrm{~m}$ with time step $\Delta t=0.00625 \mathrm{~s}$. For boundary conditions, there is a similar set up at upstream and downstream channel. The model is arranged with a water depth of $h=0.1 \mathrm{~m}$ and velocity components of $u=0.1 \mathrm{~m} / \mathrm{s}$ and $v=0 \mathrm{~m} / \mathrm{s}$.

The simulations of the turbulent jet-forced flow show that the model reached a steady state condition at 10000th iteration, with a relative error $E_{R}=1.54 \times 10^{-7}$. The optimum streamline with the required circulation length and pattern 


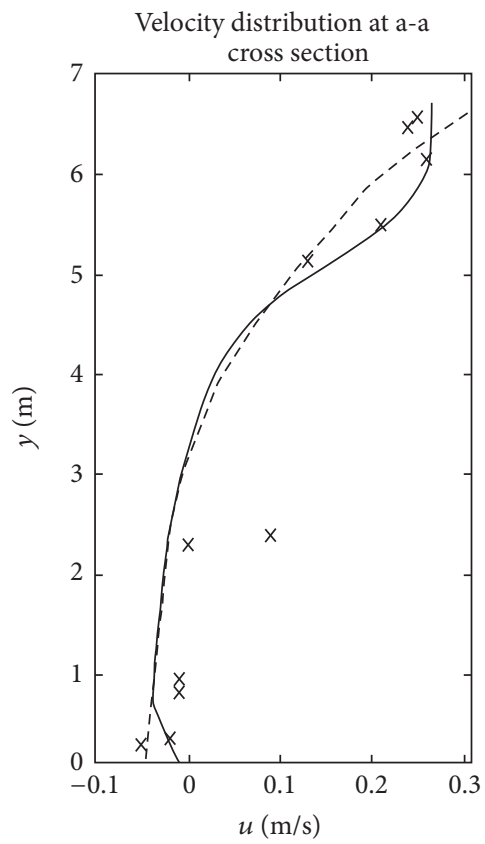

$x$ Experimental data Kuipers and Vreugdenhill (1973)

- - - Kuipers and Vreugdenhill model (1973)

— LB Model

FIgURE 5: Velocity components $u$ at the vertical (a-a) cross section [12].

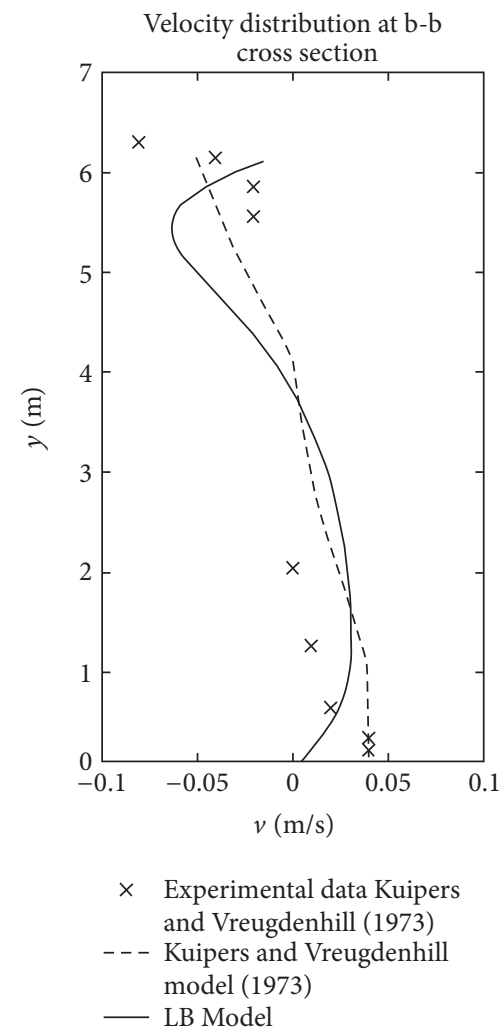

FIGURE 6: Velocity components $v$ at the horizontal (b-b) cross section [12]. 

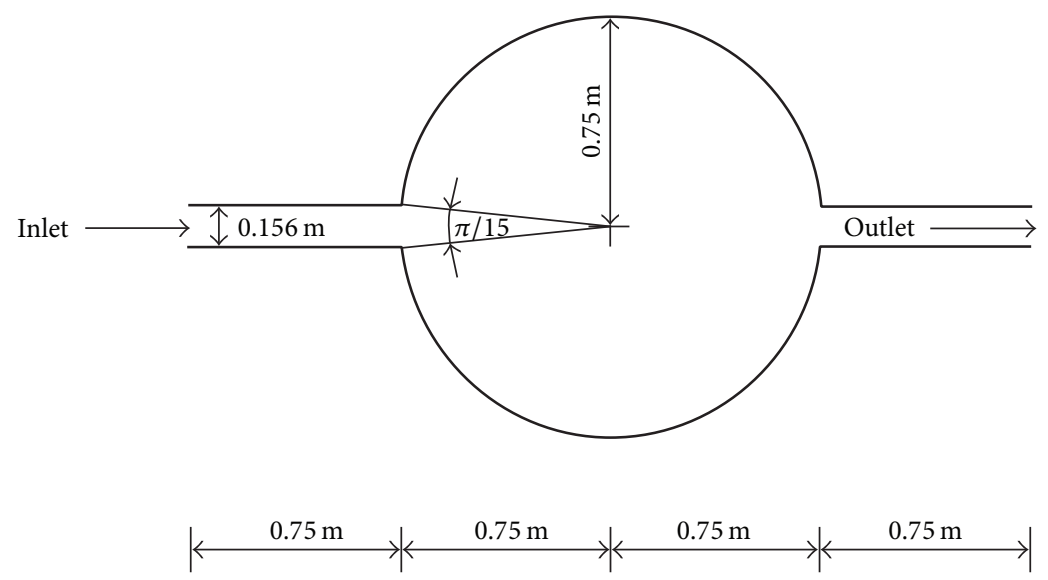

FIGURE 7: Dimension of the jet-forced flow for the symmetrical circular basin [12].

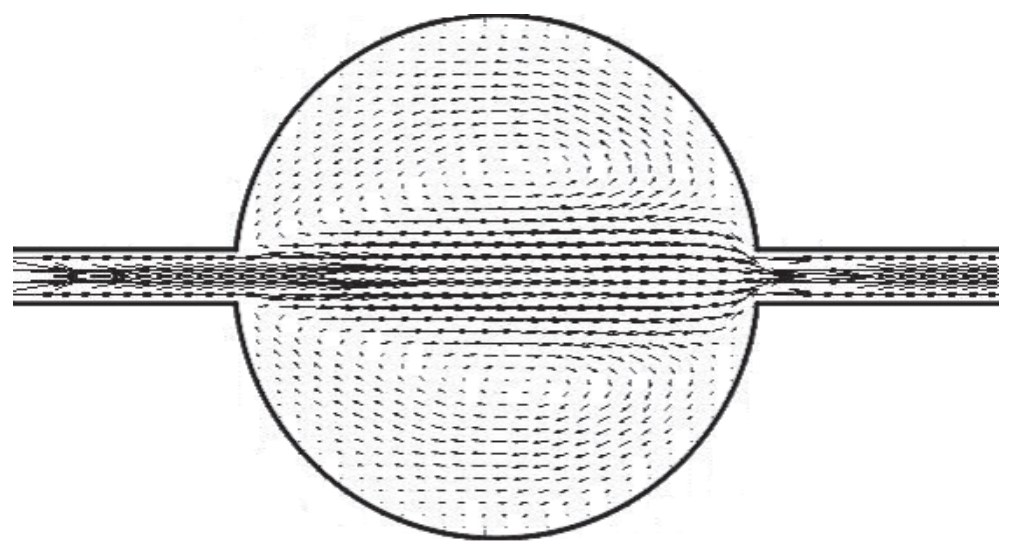

FIGURE 8: Velocity vectors of jet-forced flow in the symmetrical circular basin [12].

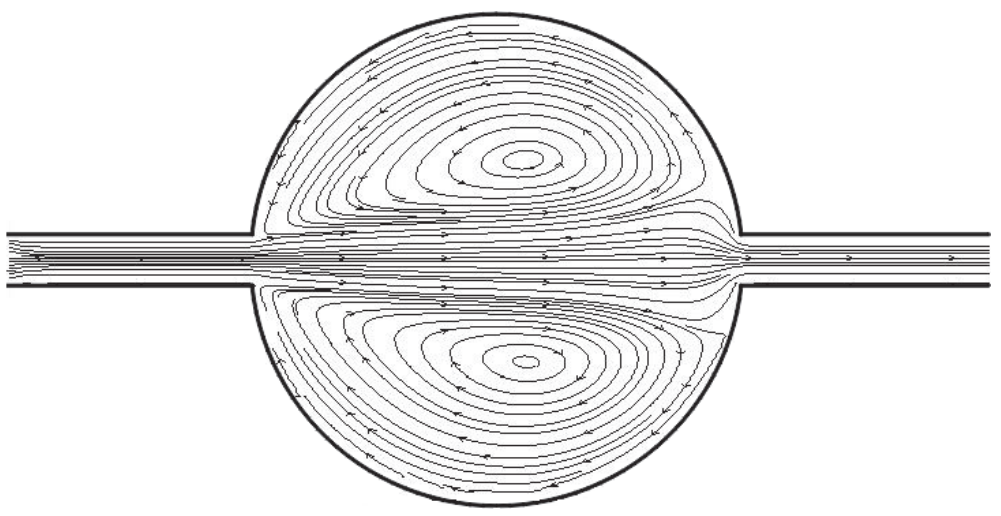

FIGURE 9: Streamline contours of jet-forced flow in the symmetrical circular basin [12].

is obtained from $\tau=0.55$ and $C_{S}=0.25$. The symmetrical channel model also generated velocity vectors of eddy and well-developed circulation flows as illustrated in Figures 8 and 9 , respectively.
The validation is done by comparing the LBM data with the numerical result by Barber's model. Figure 10 shows the velocity component, $u$ profile across the mid-section for LBM, and Barber's model. It is suggested that the LBM and 


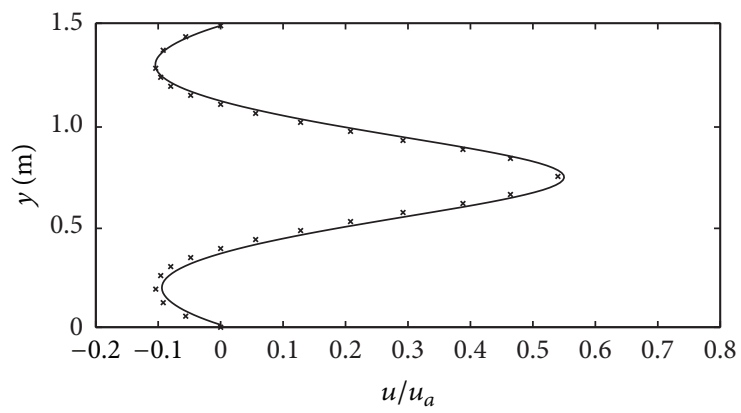

* Numerical result (Barber (1990))

- LBM

FIGURE 10: Comparison of LBM and numerical result in a circular basin [12].

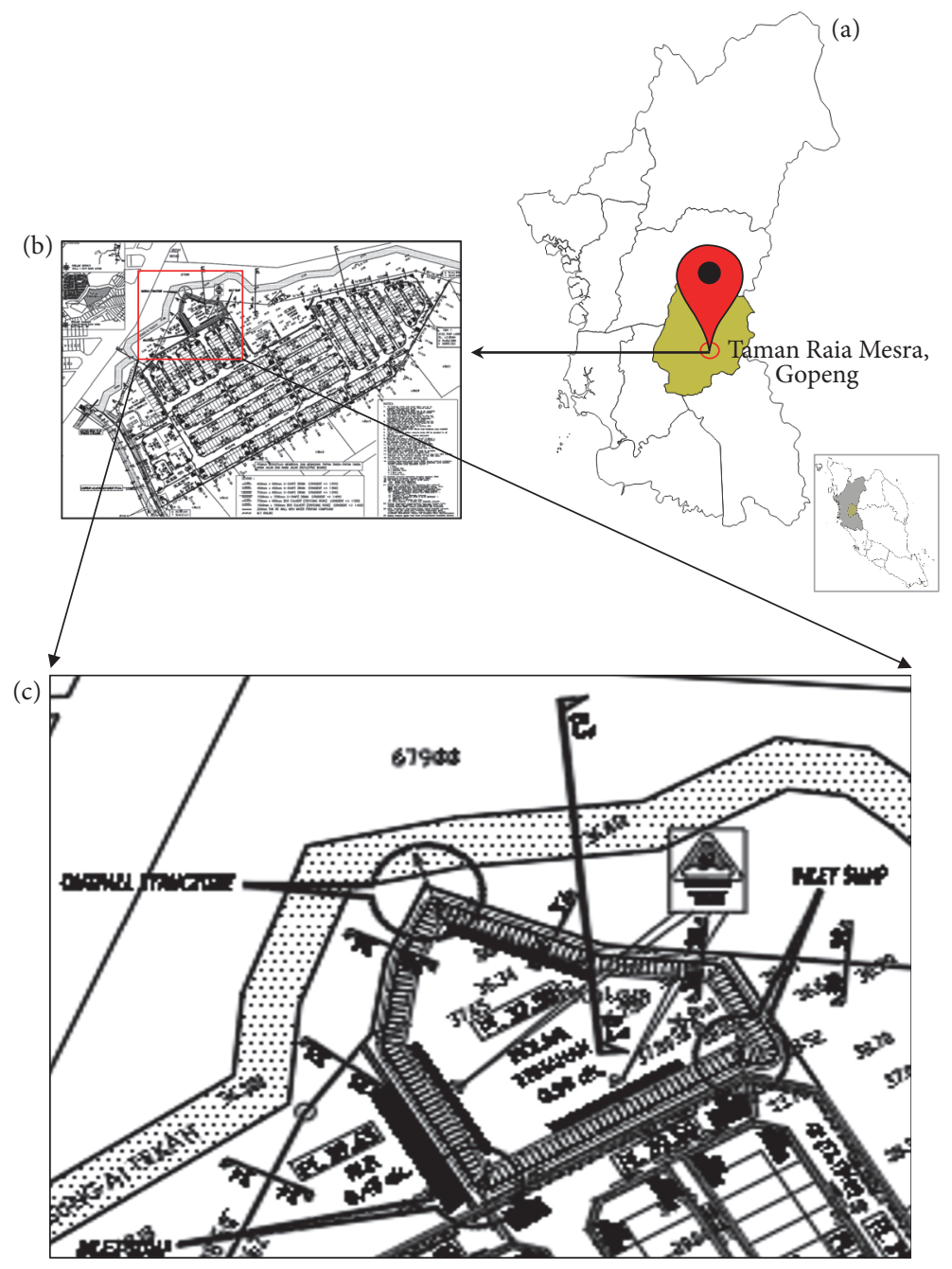

FIgURe 11: Location of the case study; Taman Raia Mesra, Gopeng, Perak. (a) Map showing the location of the study area in Perak, Malaysia. (b) Project plan at the study area. (c) Retention pond attached with the nearby river at the site.

the boundary-fitted primitive variable scheme results are in good agreement especially in the recirculation zones.

3.3. Case Study: Flood at Taman Raia Mesra, Gopeng, Perak, Malaysia. Taman Raia Mesra, Gopeng, is located at the district of Kampar, Perak, within a Peninsular Malaysia (Figure 11). This 30-acre land is a project site for the residential area. The area was flooded at the end of 2016 and is believed to occur due to the overflow of water from the nearby river basin. The retention pond found nearby the area 


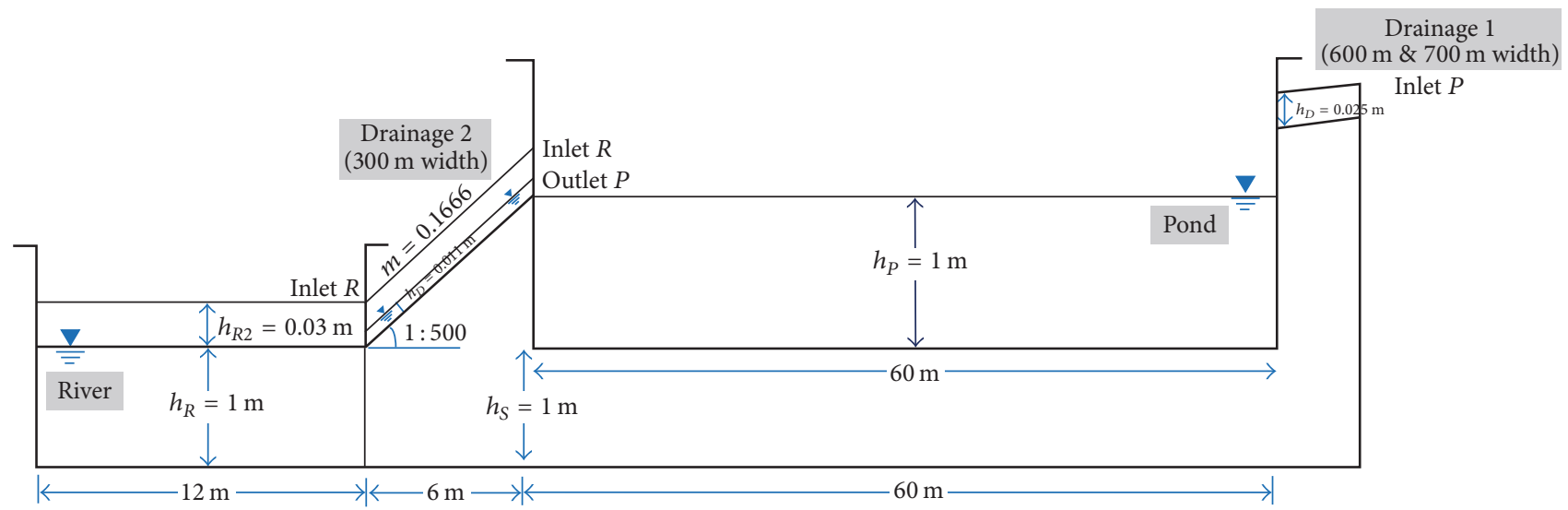

FIGURE 12: Cross section of the layout.

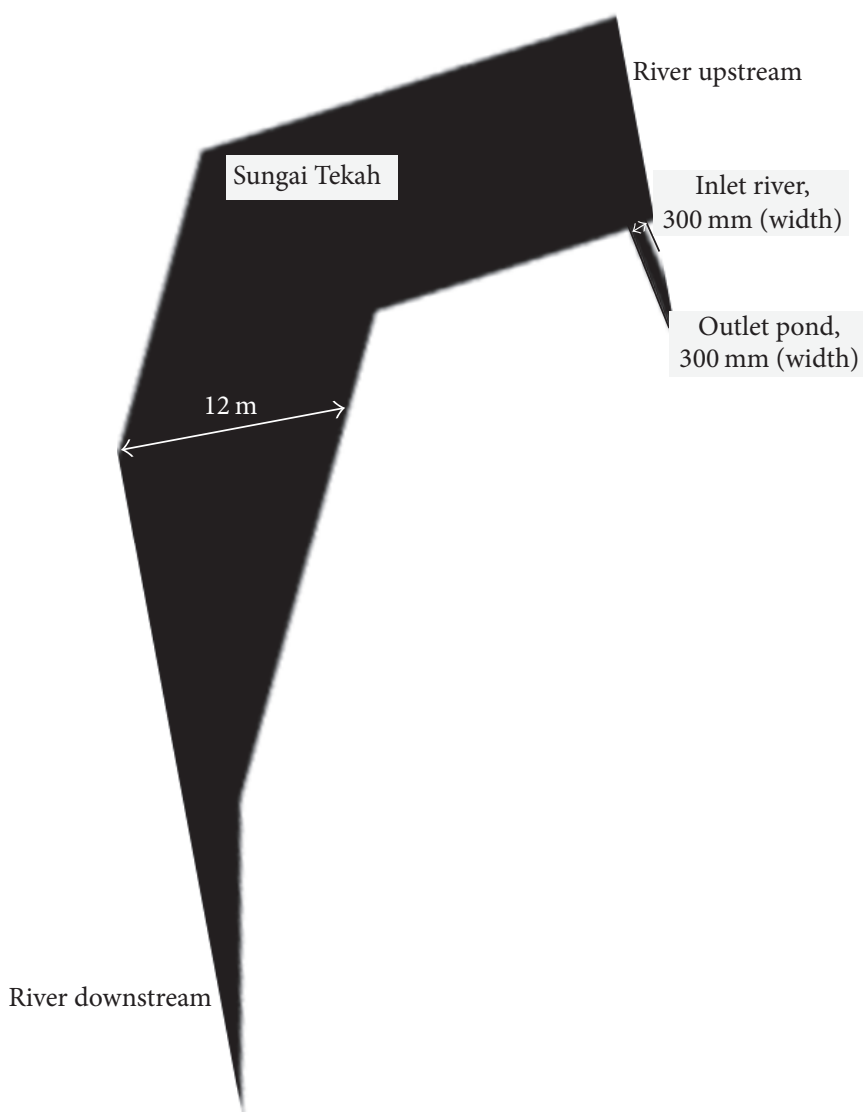

FIGURE 13: Data input for simulation showing the outlet of the pond to the river.

is a function to hold the excess water from the land and is attached to the river by a small outlet.

The cross section layout for the focusing area including a pond, outlet pond, and river is illustrated in Figure 12. The $60 \mathrm{~m}$ pond is attached with a drainage 1 as inlet pond and drainage 2 as outlet pond and inlet river in unison. In simulation test, the inlet pond is set up with a peak flow of $Q=0.0036 \mathrm{~m}^{3} / \mathrm{s}$, the height of $h_{d}=0.025 \mathrm{~m}$, and velocity in the $x$ direction of $u=0.5 \mathrm{~m} / \mathrm{s}$. Meanwhile, both outlet pond and inlet river are arranged with $Q=0.74 \mathrm{~m}^{3} / \mathrm{s}, h_{D}=0.011 \mathrm{~m}$, and $u=0.5 \mathrm{~m}$. The simulation was done in a domain area of $63.5 \mathrm{~m} \times 30.7 \mathrm{~m}$.

The LABSWE model is used to investigate the behaviour of the water flow. The simulation test was carried out by using a model resulted from a conversion of AutoCAD file into PNG image comprising a grid lattice size of $396 \times 154$ (Figure 13). The time step used is $d t=0.01$ with an iteration of 10,000. The kinematic viscosity is set up with $\tau=1.1$ and $d x=1.0$. 


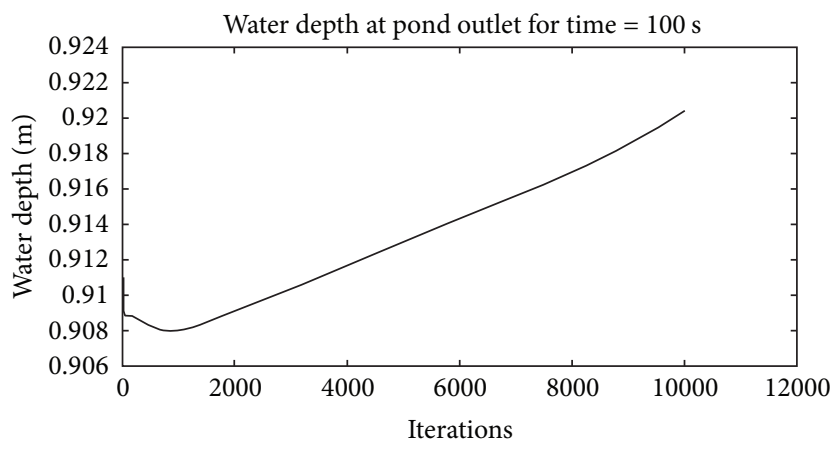

FIGURE 14: Water depth at an outlet of the pond at $100 \mathrm{~s}$.

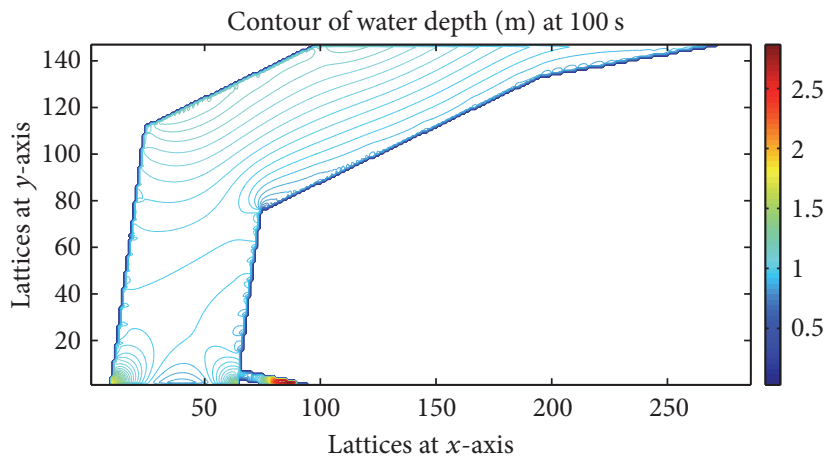

FIGURE 15: Contour of water depth at the domain area for $100 \mathrm{~s}$.

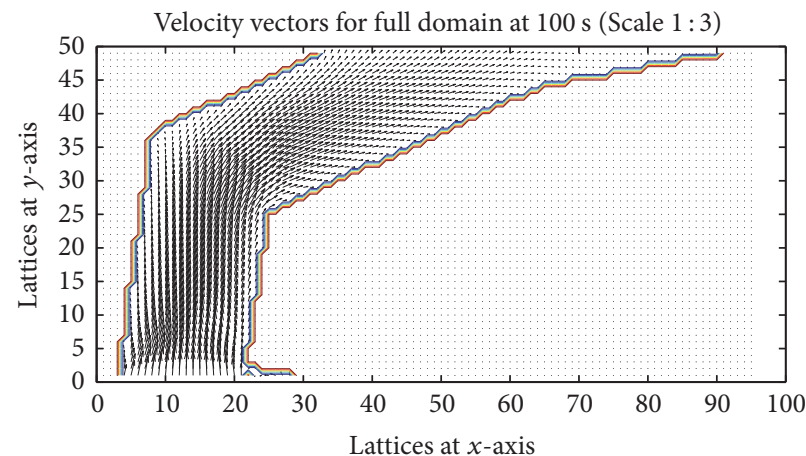

FIGURE 16: Velocity vectors for a whole domain area at $100 \mathrm{~s}$ with the scale of $1: 3$.

The simulation results were observed for every 5 seconds starting from $0 \mathrm{~s}$ up to $100 \mathrm{~s}$. The analysis revealed the water depth at the outlet of the pond and velocity profile of the domain area as plotted in Figures 14-18.

The water depth at the outlet of the pond has been recorded for $100 \mathrm{sec}$. The result shown in Figure 14 illustrated that the water depth in the outlet increased from $0.9 \mathrm{~m}$ until $0.92 \mathrm{~m}$. There are no significant changes of water profile observed during the simulation. However, it is noticed that a hydraulic jump profile had occurred within the channel. The occurrence can be related to a steep slope and high velocity.
Figure 15 shows a contour of water depth in the domain area. The highest water depth is observed at the beginning of the channel due to the very steep slope for the outlet. The water depth will increase with time due to the size of the outlet channel that is too small for capturing the water flow.

In order to understand the flow directions in the domain area, the figure of velocity vectors has been produced as shown in Figures 16 and 17. Figure 16 is the velocity vectors for the whole domain area. It is observed that there are no anomalies in the simulation result. However, a close-up view has been done near to the outlet pond area such as in Figure 17 shows that the water is flooding from the river into the outlet 


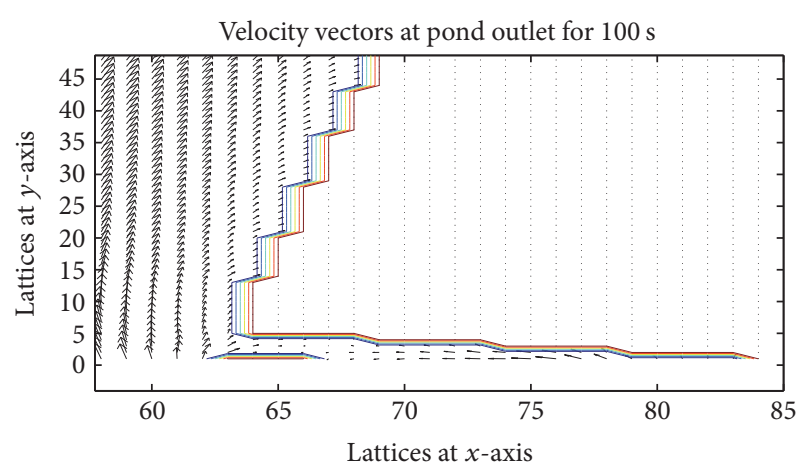

FIGURE 17: Velocity vectors for the outlet pond at $100 \mathrm{~s}$.

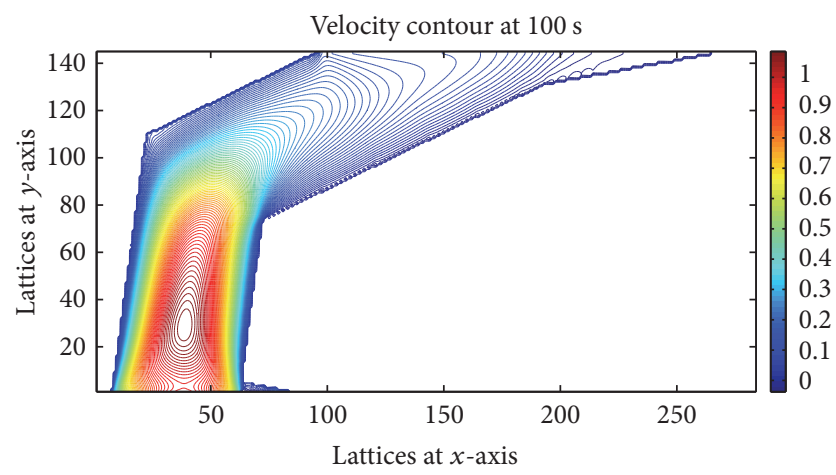

FIGURE 18: Velocity contour of water flow at $100 \mathrm{~s}$.

pond channel. This is a very significant effect that can cause flooding to the residential area.

In addition, towards the results analysis, a velocity contour of the domain area has been produced and studied as illustrated in Figure 18. The water velocity in the stream has increased from $0.5 \mathrm{~m} / \mathrm{s}$ to $1.09 \mathrm{~m} / \mathrm{s}$ due to the heavy rainfall event.

\section{Conclusions}

The LABSWE is used for simulating a flood event at Taman Raia Mesra, Gopeng, Perak. The turbulent flow and jet force flow in a circular channel had been tested for a model validation. The outcome for both validations shows a very satisfactory result. The LABSWE also has been incorporated with rainfall and storm water parameters for November 2016. The investigation had proven the incompatibility of the size of the outlet pond which is too small for the water to flow out to the river. The situation then can cause a flood to the pond area and will finally overflow to the residential area. In order to overcome this problem, equatorial countries like Malaysia should consider the heavy rainfall and stormwater discharge when designing an outlet as the country is always receiving the heavy rainfall continuously.

\section{Conflicts of Interest}

The authors declare that there are no conflicts of interest regarding the publication of this paper.

\section{Acknowledgments}

The authors appreciate the full support by research grant from MOSTI Science fund (04-02-13-SF0022). It is a pleasure to also acknowledge the Centre of Postgraduate Studies and Department of Civil and Environmental Engineering, Universiti Teknologi PETRONAS, for their support and encouragement.

\section{References}

[1] S. G. Diya, M. E. Gazim, M. E. Toriman, and M. G. Abdullahi, "Floods in Malaysia: historical reviews, causes, effects and mitigations approach," International Journal of Interdisciplinary Research and Innovations, pp. 59-65, 2014.

[2] WMO, "Role of WMO and national meteorological and hydrological services in disaster risk reduction," World Meteorological Organization, 2009.

[3] K. Y. Yoon, N. A. Bahrun, and Y. Kum, A study on the urban flooding, Universiti Malaysia Pahang, Pahang, Malaysia, 2010.

[4] S. N. Jonkman and I. Kelman, "An analysis of the causes and circumstances of flood disaster deaths," Disasters, vol. 29, no. 1, pp. 75-95, 2005.

[5] J. Janssen and R. Mayer, "Computational fluid dynamics (CFD)based droplet size estimates in emulsification equipment," Processes, vol. 4, no. 4, pp. 1-14, 2016.

[6] D. Bigoni, A. P. Engsig-Karup, and C. Eskilsson, "Efficient uncertainty quantification of a fully nonlinear and dispersive water wave model with random inputs," Journal of Engineering Mathematics, vol. 101, pp. 87-113, 2016.

[7] J. G. Zhou, Lattice Boltzmann Methods for Shallow Water Flows, Springer, Heidelberg, Germany, 2004.

[8] S. H. Shafiai, "A lattice Boltzmann model for the 2D solitary wave run-up around a conical island," in Proceedings of the Coasts, Marine Structures and Breakwaters, pp. 1-10, Edinburgh, UK, September 2013.

[9] M. Delphi, M. M. Shooshtari, and H. H. Zadeh, "Application of diffusion wave method for flood routing in Karun river," International Journal of Environmental Science and Development, pp. 432-434, 2010.

[10] A. A. Mahessar, A. L. Qureshi, and A. Baloch, "Numerical study on flood routing in Indus river," International Water Technology Journal, pp. 3-12, 2013.

[11] N. Liu, J. Feng, and J. Zhu, "Flood routing based on diffusion wave equation using lattice Boltzmann method," Procedia Engineering, vol. 28, pp. 190-195, 2012.

[12] S. H. Shafiai, Lattice Boltzmann Method for Simulating Shallow Free Surface Flows involving Wetting and Drying [Ph.D. dissertation], Liverpool University, Liverpool, UK, 2011.

[13] J. Kuipers and C. B. Vreugdenhil, "Calculations of twodimensional horizontal flow," Hydraulics Laboratory Report, Delft, The Netherlands, 1973. 


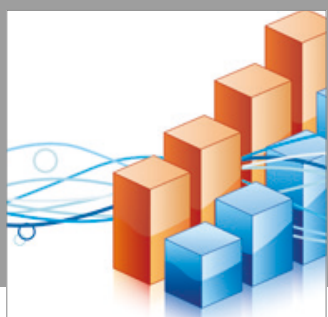

Advances in

Operations Research

vatersals

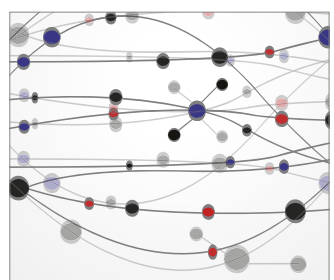

\section{The Scientific} World Journal
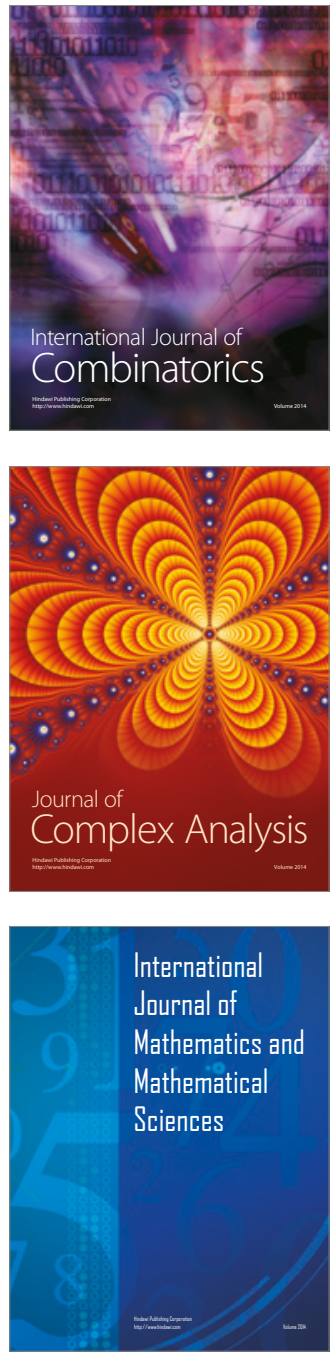
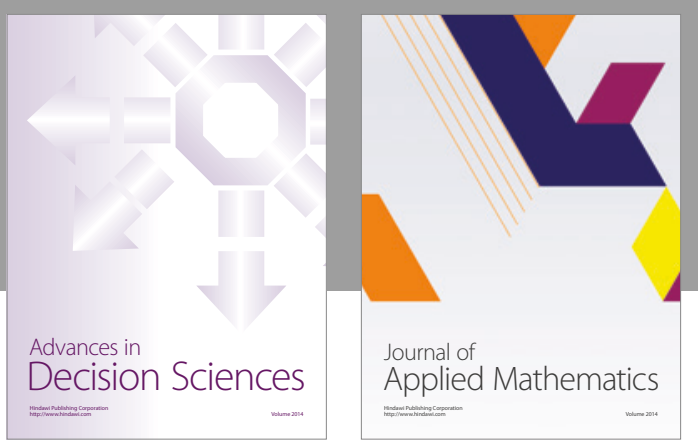

Algebra

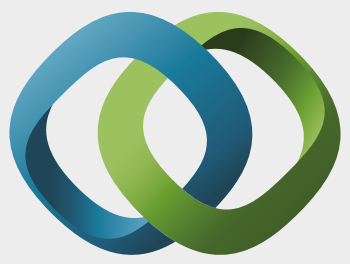

\section{Hindawi}

Submit your manuscripts at

https://www.hindawi.com
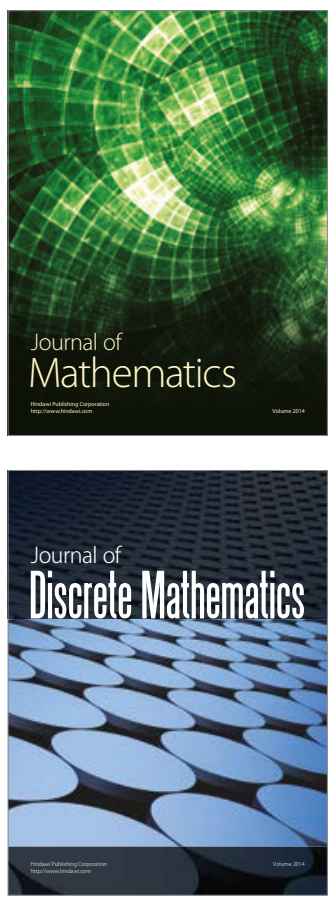

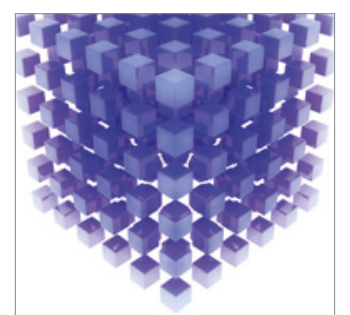

Mathematical Problems in Engineering
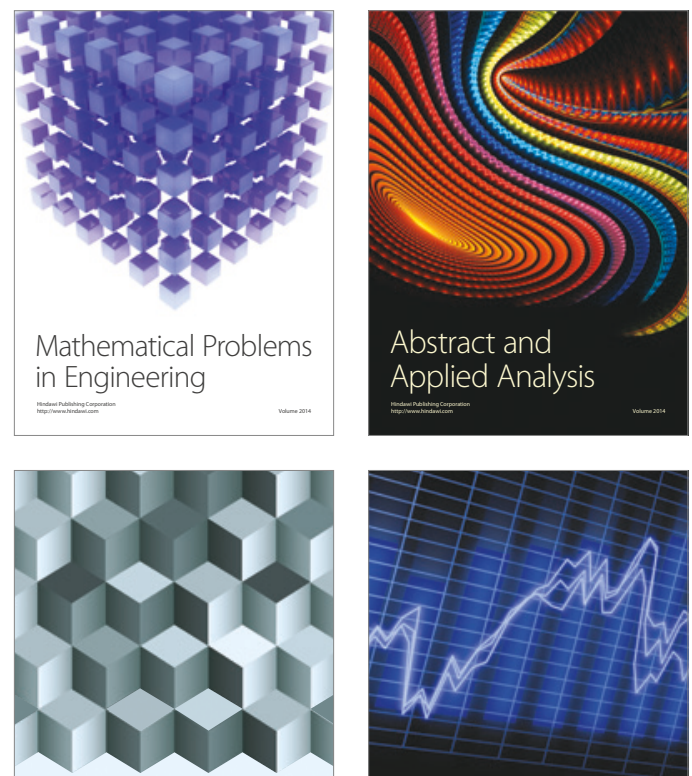

Journal of

Function Spaces

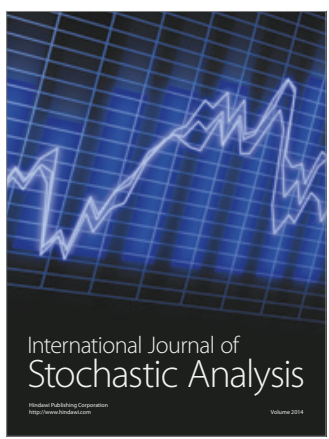

Probability and Statistics
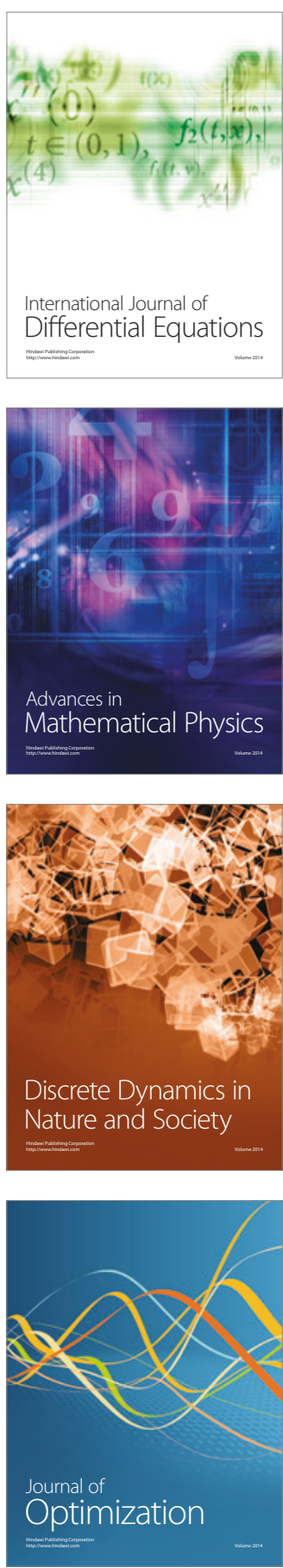